\title{
KEPUTUSAN PETANI BERALIH USAHATANI DARI TANAMAN KAKAO MENJADI LADA DI KABUPATEN LAMPUNG TIMUR
}

\section{FARMERS 'DECISIONS SWITCH OF COCONUT PLANT TO LADA IN EAST LAMPUNG DISTRICT}

\author{
Zulkarnain*, Muher Sukmayanto \\ Sekolah Tinggi Ilmu Pertanian Dharma Wacana J1. Kenagan No.3 Mulyojati 16 C, \\ Metro Barat, Kota Metro, Lampung \\ *Email: zulfadhilalzabir@gmail.com \\ (Diterima 11-03-2019; Disetujui 19 Juli 2019)
}

\begin{abstract}
ABSTRAK
Penelitian ini bertujuan untuk mengetahui keputusan petani beralih usahatani dari tanaman kakao menjadi tanaman lada di Kabupaten Lampung Timur. Lokasi penelitian di Kecamatan Sukadana dan Kecamatan Margatiga Kabupaten Lampung Timur. Responden dalam penelitian ini adalah petani lada dan petani kakao di Kecamatan Sukadana dan Kecamatan Margatiga Kabupaten Lampung Timur sebanyak 67 petani yang dipilih dengan metode acak sederhana (simple random sampling). Untuk menjawab tujuan penelitian digunakan analisis logit. Hasil penelitian yang didapatkan adalah faktor yang mempengaruhi keputusan petani beralih usahatani dari tanaman kakao ke lada adalah usia petani, tanggungan keluarga, pengalaman usahatani, dan pendapatan.
\end{abstract}

Kata kunci: Alih Tanaman, Kakao, Keputusan, Lada

\section{ABSTRACT}

This study aims to determine the decision of farmers to switch farming from cocoa plants to pepper plants in East Lampung Regency. The location of this study was conducted in Sukadana District and Margatiga District, East Lampung Regency. Respondents in this study were pepper farmers and cocoa farmers in Sukadana District and Margatiga District, East Lampung Regency, as many as 67 farmers who were selected by simple random sampling. To answer the research objectives, it is logit analysis. The results of the research obtained are factors that influence farmers' decision to switch farming from cocoa to pepper crops they are farmer's age, family dependence, farming experience, and income.

Keywords: Decision, Cocoa, Crop Transfer, Pepper

\section{PENDAHULUAN}

Komoditas ekspor dari subsektor tanaman perkebunan yang mempunyai peranan penting dalam perekonomian negara adalah lada (Piper nigrum L.) dan kakao (Sumantri et al, 2004; Syamsuddin dan muhammad, 2014; Rizal et al, 2017). Indonesia merupakan salah satu dari tiga negara pengekspor kakao dunia yang sebagian besar dalam bentuk biji (Fitriana et al, 2014). Oleh karena itu, prospek atau peluang pasar kakao dunia terus mengalami peningkatan dari tahun ke tahun (Maulana dan Kartiasih, 2017).

Nilai ekspor komoditas pertanian selama tahun 2017 sebesar USD 2,61 milyar dan sebagian besar disumbang dari subsektor tanaman perkebunan yakni sebesar USD 2,52 atau 96,43 \% (Kementerian Pertanian, 2018). 


\section{KEPUTUSAN PETANI BERALIH USAHATANI DARI TANAMAN KAKAO MENJADI LADA \\ DI KABUPATEN LAMPUNG TIMUR \\ Zulkarnain, Muher Sukmayanto}

Komoditas kakao menjadi komoditas andalan bagi Indonesia, hal ini dikarenakan tanaman kakao memiliki potensi yang besar sebagai komoditas ekspor. Tetapi tanaman kakao menghadapi berbagai masalah yang cukup rumit. Salah satunya adalah $80 \%$ tanaman kakao yang diekspor dalam bentuk bahan mentah (biji kakao) (Suryana et al, 2014).

Indonesia merupakan negara produsen kakao terbesar dunia tetapi produktifitas dan mutuhnya masih rendah, sehingga diperlukan perawatan tanaman kakao secara intensif (Pattiasina-Suripatty dan Mussa, 2012). Berkurang atau bertambahnya jumlah kakao dipengaruhi oleh faktor iklim dan cuaca yang tidak menentu sehingga kualitas kakao cenderung menurun dan paling dominan terserang hama serta penyakit seperti hama PBK, hama PB Helopeltis, Ulat kilan, Antraknose Colletotrichum, hama VSD, Jamur upas Penyakit akar, Kelayuan pentil (Riani, 2015).

Tanaman kakao memiliki banyak masalah dan kendala yang berdampak pada produktivitas kakao. Rendahnya tingkat produktivitas perkebunan disebabkan karena tanaman perkebunan rakyat yang berasal dari benih tidak unggul, kurang melakukan perawatan yang cukup pada tanaman yang diusahakan dan penguasaan teknologi produksi yang masih sangat rendah (Nurfathiyah et al, 2007). Produktivitas yang rendah tersebut berpengaruh terhadap pendapatan petani (Syamsuddin dan muhammad, 2014). Produktivitas tidak terlepas dari kualitas atau mutu dari tanaman. Penyebab rendahnya kualitas kakao Indonesia yaitu biji kakao belum difermentasi, terbatasnya sarana pengolahan, kurangnya pengawasan kualitas dan penerapan teknologi pada pengolahan biji kakao yang masih sederhana (Rubiyo dan Siswanto, 2012). Selain itu, adanya pengaruh jamur, serangan serangga, dan kotoran yang tinggi pada biji kakao. Sehingga harga biji kakao menjadi rendah akibat adanya pemotongan harga (Hasibuan et al, 2012).

Salah satu tanaman perkebunan selain kakao yang memiliki potensi untuk terus dikembangkan adalah tanaman lada. Produksi lada Indonesia sebagian besar diperuntukkan untuk ekspor. Neraca perdagangan lada Indonesia hingga tahun 2014 masih berada pada posisi surplus (Suwanto, 2017). Di Indonesia, tanaman lada sudah dibudidayakan sejak ratusan tahun yang lalu. Daerah sentral produksi utama lada di Indonesia adalah Propinsi Lampung untuk lada hitam dan Propinsi Bangka Belitung untuk lada putih. Menurut data BPS Propinsi Lampung 
tahun 2015, komoditas lada merupakan komoditas ekspor utama setelah kopi.

Kabupaten yang memberikan kontribusi produksi tanaman lada dan kakao di Propinsi Lampung adalah Kabupaten Lampung Timur. Tanaman lada telah menjadi lokasi cagar budidaya lada hitam. Sehingga petani kakao menilai tanaman lada memiliki prospek yang baik. Seiring berjalannya usahatani kakao di Kecamatan Margatiga Kabupaten Lampung Timur, tanaman kakao mengalami penurunan produksi. Rendahnya produksi kakao disebabkan oleh tingginya serangan hama penyakit (terutama PBK dan VSD), tanaman berumur tua, dan rendahnya inovasi teknologi budidaya kakao (Syamsuddin dan Muhammad, 2014).

Menurut Makeham dan Malcolm (1991), pengambilan keputusan biasanya berkaitan dengan serangkaian tindakan dari sejumlah alternatif untuk mencapaian beberapa tujuan petani. Hal tersebut diperjelas Suratiyah (2006) dalam Apriliana dan Mustadjab (2016), petani sebagai manajer harus dapat mengambil keputusan dengan berbagai pertimbangan ekonomi seperti pendapatan. Penggantian tanaman dari tanaman kakao menjadi tanaman lada disebabkan oleh tingkat pendapatan yang dihasilkan oleh tanaman kakao tidak tentu oleh faktor iklim dan cuaca yang tidak menentu sehingga kualitas kakao cenderung menurun dan paling dominan terserang hama serta penyakit. Hal tersebut menunjukkan bahwa tanaman lada masih cukup baik untuk terus dikembangkan, kondisi tersebut didukung oleh harga lada yang relatif stabil sehingga menjadi lebih tertarik meningkatkan produksi tanaman lada pada lahan usahataninnya. Beralihnya suatu komoditi tanaman merupakan keputusan yang tidak mudah karena usaha perkebunan merupakan investasi jangka panjang. Apakah faktor yang mempengaruhi keputusan petani beralih usahatani dari tanaman kakao menjadi tanaman lada di Kabupaten Lampung Timur?

\section{METODE PENELITIAN}

Lokasi penelitian di Kecamatan Sukadana dan Kecamatan Margatiga Kabupaten Lampung Timur dengan pertimbangan sebagai berikut: Kecamatan Margatiga merupakan salah satu sentral produksi lada di Kabupaten Lampung Timur, (2) Kecamatan Margatiga dikenal sebagai lokasi cagar budidaya lada hitam di Kabupaten Lampung Timur, dan (3) Kecamatan Sukadana merupakan daerah yang banyak beralih usahatani tanaman kakao ke tanaman lada. 


\section{KEPUTUSAN PETANI BERALIH USAHATANI DARI TANAMAN KAKAO MENJADI LADA \\ DI KABUPATEN LAMPUNG TIMUR \\ Zulkarnain, Muher Sukmayanto}

Teknik pengambilan sampel menggunakan perhitungan (Sugiarto et al, 2003) dengan metode acak sederhana (simple random sampling). Didapatkan jumlah sampel sebanyak 67 responden. Kemudian dilakukan perhitungan proporsional diperoleh jumlah sampel 56 petani lada dan 11 petani kakao.

Penelitian ini menggunakan dua metode, yaitu metode deskriptif dan metode inferensia. Jenis data yang dipergunakan yaitu data primer adalah data yang didapatkan dari hasil wawancara atau observasi secara langsung pada petani tanaman kakao dan tanaman lada Kecamatan Sukadana dan Kecamatan Margatiga Kabupaten Lampung Timur. Data sekunder adalah data yang diperoleh dari dokumen yang dimiliki oleh lembaga terkait/instansi terkait, laporan-laporan, publikasi dan pustaka lainnya yang berhubungan dengan penelitian ini. Teknik pengumpulan data dalam penelitian ini menggunakan instrumeninstrumen antara lain interview (wawancara), observasi (pengamatan langsung), dokumentasi, dan kuesioner.

Analisis data yang digunakan dalam penelitian ini yaitu analisis pendapatan dan regresi logistik (logit) biner. Analisis pendapatan digunakan untuk mengetahui nilai pendapatan yang diperoleh dengan rumus Soekartawi (1990) sebagai berikut:

$$
\pi=Y \cdot P_{y}-\sum X_{i} P_{x i}
$$

Keterangan:

$$
\begin{aligned}
\pi & =\text { Pendapatan }(\mathrm{Rp}) \\
Y & =\text { Hasil produksi }(\mathrm{kg}) \\
P_{y} & =\text { Harga hasil produksi }(\mathrm{Rp}) \\
X_{i} & =\text { Faktor produksi }(\mathrm{i}=1,2,3, \ldots ., \mathrm{n}) \\
P_{x i} & =\text { Harga faktor produksi ke } 1
\end{aligned}
$$

Analisis regresi logistik (logit) biner untuk melihat pengaruh keputusan petani beralih usahatani dari tanaman kakao menjadi tanaman lada. Model logit diturunkan berdasarkan fungsi peluang logistik yang dapat dispesifikasikan sebagai berikut (Widarjono, 2016):

$$
\begin{aligned}
Z_{i}= & \ln \frac{P_{i}}{1-P_{i}} \\
Z_{i}= & \alpha+\beta_{1} X_{1}+\beta_{2} X_{2}+\beta_{3} X_{3}+\beta_{4} X_{4}+\beta_{5} X_{5}+ \\
& \beta_{6} X_{6}+\mu
\end{aligned}
$$

Keterangan:

$$
\begin{aligned}
& \mathrm{P}_{\mathrm{i}}=\text { Keputusan petani beralih } \\
& \beta_{0}=\text { Intersep } \\
& \beta_{1} \ldots \beta_{\mathrm{i}}=\text { Koefisien regresi } \\
& \mathrm{X}_{1} \quad=\text { Umur petani } \\
& \mathrm{X}_{2} \quad=\text { Pendidikan } \\
& \mathrm{X}_{3} \quad=\text { Jumlah tanggungan } \\
& \mathrm{X}_{4} \quad=\text { Pengalaman berusahatani } \\
& \mathrm{X}_{5} \quad=\text { Luas lahan } \\
& \mathrm{X}_{6} \quad=\text { Pendapatan } \\
& \mu \quad=\text { Pengganggu }
\end{aligned}
$$

Pengujian dilakukan untuk melihat apakah model logit yang dihasikan secara keseluruhan dapat menjelaskan keputusan pilihan, dalam hal ini uji yang digunakan adalah Hosmer and Lameshow test 
dengan melihat nilai Chi-square dan nilai

Negelkerke $R$ Square dan Rasio Kecederungan (Odds Ratio).

HASIL DAN PEMBAHASAN

\section{A. Analisis Pendapatan}

Analisis pendapatan digunakan untuk mengetahui pendapatan usahatani kakao dan usahatani lada yang dapat dilihat pada Tabel 1.

Tabel 1. Analisis pendapatan usahatani kakao dan lada di Kabupaten Lampung Timur per hektar

\begin{tabular}{llrr}
\hline No. & \multicolumn{1}{c}{ Variabel } & Usahatani Kakao & Usahatani Lada \\
\hline 1 & Produksi (Kg/Ha) & $1.388,47$ & 980,29 \\
2 & Harga (Rp.) & $27.675,68$ & $49.055,21$ \\
3 & Penerimaan (Rp./Ha) & $29.432 .792,79$ & $33.113 .128,83$ \\
4 & Biaya Total (Rp./Ha) & $12.229 .131,74$ & $7.343 .676,17$ \\
\hline & Pendapatan (Rp./Ha) & $17.203 .661,06$ & $25.769 .452,67$ \\
\hline
\end{tabular}

Sumber: Data primer (diolah), 2018

Tabel 1 menunjukkan bahwa ratarata pendapatan per hektar usahatani lada lebih tinggi dibandingkan rata-rata pendapatan usahatani kakao. Pendapatan usahatani lada sebesar Rp 25.769.452,67 dan usahatani kakao sebesar Rp 17.203.661,06. Perbedaan tersebut dikarenakan usahatani lada memiliki ratarata harga per hektar lebih tinggi dibandingkan rata-rata harga tanamana kakao.

Tinggi rendahnya pendapatan petani dipengaruhi oleh besarnya biaya yang dikeluarkan dalam mengusahakan usahatani (Kaplale, 2011), hal ini dilihat dari biaya usahatani kakao lebih besar daripada usahatani lada. Besarnya biaya produksi kakao dikarenakan tanaman kakao rentan terhadap penyakit hama tanaman dan membutuhkan tenaga kerja pemeliharaan serta tenaga kerja panen yang dilakukan setiap minggu secara rutin. Walaupun produksi kakao lebih besar dibandingkan produksi lada tapi tidak diimbangi dengan harga yang baik sehingga mempengaruhi pendapatan petani.

\section{B. Analisis Faktor-faktor yang Mempengaruhi Keputusan Petani Beralih Tanaman Kakao ke Tanaman Lada}

Faktor-faktor yang mempengaruhi keputusan petani beralih tanaman dari tanaman kakao ke tanaman lada adalah umur petani, pendidikan petani, luas lahan, pendapatan, pengalaman berusahatani, dan jumlah tanggungan petani. Model yang digunakan untuk menganalisis faktor-faktor yang mempengaruhi keputusan petani terhadap peralihan tanaman kakao ke lada adalah model logit linier dengan variabel dependen (tidak bebas) yang bernilai kuantitaf dengan dua katagori nilai 


\section{KEPUTUSAN PETANI BERALIH USAHATANI DARI TANAMAN KAKAO MENJADI LADA \\ DI KABUPATEN LAMPUNG TIMUR \\ Zulkarnain, Muher Sukmayanto}

(biner). Katagori nilai dalam pengantian jenis tanaman tersebut yaitu nilai skor 1 (satu) untuk katagori keputusan petani untuk menanam lada dan nilai skor 0 (nol) untuk katagori petani yang tetap mempertahankan usahatani kakao.

Pengujian signifikansi pada regresi logistik dapat dibagi menjadi dua yaitu pengujian secara simultan dan pengujian secara parsial. Pengujian secara individual atau parsial dapat dilakukan dengan Uji Wald. Sedangkan pengujian secara simultan atau serentak dilakukan dengan menggunakan Uji Overal Model Fit.

\section{Menilai Keseluruhan Model (Overall Model Fit)}

Uji overall model fit adalah uji statistik untuk mengetahui apakah semua variabel independen di dalam regresi logistik secara serentak mempengaruhi variabel dependen sebagai mana uji $\mathrm{F}$ dalam regresi linier didasarkan pada nilai statistika -2LL atau nilai LR. Uji serentak koefisien regresi model logistik dihitung dari perbedaan nilai -2LL antara model dengan hanya menggunakan konstanta dan model yang diestimasi dengan semua variabel independen (Widarjono, 2016).

Uji LR mengikuti distribusi Chi Square dengan derajat bebas (degree of freedom) n-k. Jika Chi square dapat dilihat melalui Hosmer and Lemeshow test pada Tabel 2.

Tabel 2. Hosmer and Lemeshow Test

\begin{tabular}{cccc}
\hline Step & Chi-square & Df & Sig. \\
& & \\
\hline 1 & 3.863 & 8 & .869 \\
\hline Sumber: Data primer (diolah), 2018
\end{tabular}

Tabel 2 menunjukkan bahwa model regresi logistik sudah memenuhi asumsi kelayakan model yang dapat dilihat dari nilai chi square hitungnya sebesar 4,584 nilai ini lebih kecil dari nilai chi square tabel (pada $\mathrm{df}=8$ dan alpha 5\%) sebesar $15,507(3,863<15,507)$.

Kelayakan model dapat dilihat dari nilai sign yang lebih besar dari alpha 5\% $(1,000>0,05)$, yang berarti tidak signifikan ( $\mathrm{H}_{0}$ diterima). Hal ini berarti model regresi binari logistik layak dipakai untuk analisis selanjutnya, karena tidak ada perbedaan nyata antara klasifikasi yang diprediksi dengan klasifikasi yang diamati. Dapat disimpulkan bahwa variabel independen seperti umur $\left(\mathrm{X}_{1}\right)$, tingkat pendidikan $\left(\mathrm{X}_{2}\right)$, jumlah tanggungan keluarga $\left(\mathrm{X}_{3}\right)$, pengalaman usahatani $\left(\mathrm{X}_{4}\right)$, luas lahan $\left(\mathrm{X}_{5}\right)$, dan pendapatan $\left(\mathrm{X}_{6}\right)$ secara serentak mempengaruhi keputusan petani beralih tanaman kakao ke tanaman lada. Untuk mengetahui seberapa baik model mengelompokkan kasus penelitian keputusan petani beralih tanaman kakao 
ke tanaman lada dapat dilihat pada Tabel

3.

Tabel 3. Clasificasion tabel

\begin{tabular}{llccc}
\hline Observed & \multicolumn{3}{c}{ Predicted } \\
\cline { 3 - 4 } & & \multicolumn{2}{c}{ Keputusan (Y) } & Percentage Correct \\
\cline { 3 - 4 } & & Kakao & Lada & \\
\hline Keputusan (Y) & Kakao & 4 & 7 & 36,4 \\
& Lada & 4 & 52 & 92,9 \\
\hline Overall Percentage & & & & 83,6 \\
\hline
\end{tabular}

Sumber: Data primer (diolah), 2018

Tabel 3 menunjukkan bahwa keakuratan prediksi adanya variabel umur (X1), tingkat pendidikan (X2), jumlah tanggungan (X3), pengalaman usahatani (X4), luas lahan (X5), dan pendapatan (X6) sebesar 83,6\%. Hal ini menunjukkan seberapa baik model mengelompokkan penelitian ke dalam kelompok petani

\section{Koefisien Determinasi (Nagelkerke} R Square)

Koefisien determinasi $\left(\mathrm{R}^{2}\right)$ di dalam regresi logistik mengukur proporsi varian di dalam variabel dependen yang dijelaskan oleh variabel independen. Namun koefesien determinasi $\left(\mathrm{R}^{2}\right)$ sebagai ukuran kebaikan garis regresi adalah ukuran yang kurang baik (poor measure) di dalam regresi logistik, tidak sebagaimana di dalam regresi linier. Karena itu, sebagai ukuran kebaikan garis regresi di dalam regresi logistik disebut dengan ukuran yang palsu (Pseudo $\mathrm{R}^{2}$ ) (Widarjono, 2016)

Ada dua ukuran Pseudo $\mathrm{R}^{2}$ yang biasa digunakan untuk mengukur kakao yang beralih menanam lada. Model yang dibangun cukup baik karena ada peningkatan keakuratan prediksi secara menyeluruh. Tingkat keakuratan petani tetap menanam kakao dan petani yang beralih menanam lada masing-masing sebesar 36,4\% dan 92,9\%.

kebaikan garis regresi pada model regresi logistik yaitu Pscedo $R^{2}$ Cox and Snell dan Pscedo $R^{2}$ Nagelkerke (Widarjono, 2015). Cox \& Snell $R$ Square merupakan ukuran yang mencoba meniru ukuran $R$ Square pada multiple regression yang didasarkan pada teknik estimasi likelihood dengan nilai maksimum kurang dari 1 sehingga sulit untuk diinterpretasikan. Oleh karena itu, Nagelkerke R Square yang merupakan modifikasi dari Cox \& Snell $R$ Square di mana nilainya bervariasi dari $0-1$, akan lebih mudah untuk diinterpretasikan sebagaimana interpretasi atas $R$ Square pada multiple regression atau Pseudo $R$ Square dalam multinominal logistic regression. Pada penelitian ini nilai Cox 


\section{KEPUTUSAN PETANI BERALIH USAHATANI DARI TANAMAN KAKAO MENJADI LADA \\ DI KABUPATEN LAMPUNG TIMUR \\ Zulkarnain, Muher Sukmayanto}

and snell $R$ Square dan nilai $R^{2}$ Negelkerke pada Tabel 4.

Tabel 4. Model Summary

\begin{tabular}{cccc}
\hline Step & $\begin{array}{c}-2 \text { Log } \\
\text { likelihood }\end{array}$ & $\begin{array}{c}\text { Cox \& } \\
\text { Snell R } \\
\text { Square }\end{array}$ & $\begin{array}{c}\text { Nagelkerke } \\
\text { R Square }\end{array}$ \\
\hline 1 & $37.317^{\mathrm{a}}$ & .285 & .483 \\
\hline
\end{tabular}

Sumber: Data primer diolah, 2018

Tabel 4 menunjukkan bahwa uji goodness of fit model logit menghasilkan nilai Negelkerke $R$ Square $\left(\mathrm{R}^{2}\right)$ sebesar 0,483 atau 48,30 \%. Hal ini berarti, variabel dependen secara serentak dapat dijelaskan oleh variabel independen seperti umur $\left(\mathrm{X}_{1}\right)$, tingkat pendidikan $\left(\mathrm{X}_{2}\right)$, jumlah tanggungan keluarga $\left(\mathrm{X}_{3}\right)$, pengalaman usahatani $\left(\mathrm{X}_{4}\right)$, luas lahan $\left(\mathrm{X}_{5}\right)$, dan pendapatan (X6) sebesar 48,30 $\%$ sedangkan sisanya sebesar 51,70\% dipengaruhi atau dijelaskan oleh variabelvariabel yang tidak dimasukkan dalam penelitian model ini.

\section{Uji Wald}

Uji Wald digunakan untuk menguji ada tidaknya pengaruh dari variabel bebas terhadap variabel terikat secara parsial dengan cara membandingkan nilai statistik Wald dengan nilai pembanding Chi square pada derajat bebas $(\mathrm{db})=1$ pada alpha 5\%, atau dengan membandingkan nilai signifikansi (pvalue) dengan alpha sebesar 5\% dimana pvalue yang lebih kecil dari alpha menunjukkan bahwa hipotesis diterima atau terdapat pengaruh yang signifikan dari variabel bebas terhadap variabel terikat secara parsial

Uji wald (Uji t) digunakan untuk mengetahui faktor-faktor yang berpengaruh terhadap keputusan petani kakao beralih ke tanaman lada, untuk lebih jelasnya dapat dilihat pada Tabel 5.

Tabel 5. Uji wald faktor-faktor yang mempengaruhi keputusan petani beralih tanaman kakao ke tanaman lada

\begin{tabular}{lccc}
\multicolumn{1}{c}{ Variabel } & Koefisien B & P value & $\begin{array}{c}\text { Exp (B) atau Odds } \\
\text { Ratio }\end{array}$ \\
\hline Usia $\left(\mathrm{X}_{1}\right)$ & & & 0,851 \\
Tingkat pendidikan $\left(\mathrm{X}_{2}\right)$ & $-0,161^{* * *}$ & 0,015 & 0,810 \\
Tanggungan Keluarga $\left(\mathrm{X}_{3}\right)$ & $-0,210$ & 0,338 & 2,965 \\
Pengalaman usahatani $\left(\mathrm{X}_{4}\right)$ & $1,087^{*}$ & 0,062 & 1,153 \\
Luas lahan $\left(\mathrm{X}_{5}\right)$ & $0,142^{*}$ & 0,069 & 3,589 \\
Pendapatan $\left(\mathrm{X}_{6}\right)$ & 1.278 & 0,259 & 1,001 \\
Y $(1=$ Beralih ke tanaman lada; $0=$ Tidak & $0,001^{* *}$ & 0,036 & 13,700 \\
beralih tanaman) Intersep & 2,617 & 0,478 &
\end{tabular}

Negalkerke R square

0,483

Sumber : Data primer (diolah), 2018

Keterangan: $* * *, * *, *$ signifikan pada $\alpha 1 \%, 5 \%, 10 \%$

Tabel 5 menunjukkan bahwa model persamaan regresi faktor-faktor yang mempengaruhi petani beralih tanaman kakao menjadi tanaman lada adalah: 


$$
Y=2,617-0,161 X_{1}-0,210 X_{2}+1,087 X_{3}+0,142 X_{4}+1,278 X_{5}+0,001 X_{6}+e
$$

Dengan menggunakan uji t terlihat variabel usia $\left(\mathrm{X}_{1}\right)$, tanggungan keluarga $\left(\mathrm{X}_{3}\right)$, pengalaman usahatani $\left(\mathrm{X}_{4}\right)$, dan pendapatan $\left(\mathrm{X}_{6}\right)$ berpengaruh nyata terhadap petani beralih tanaman kakao menjadi tanaman lada. Sedangkan variabel tingkat pendidikan $\left(\mathrm{X}_{2}\right)$ dan luas lahan $\left(\mathrm{X}_{5}\right)$ tidak berpengaruh nyata.

Pengaruh masing-masing variabel terhadap keputusan petani beralih tanaman kakao menjadi tanaman lada dapat dijelaskan sebagai berikut:

Usia $\left(X_{1}\right)$, variabel usia berpengaruh nyata terhadap keputusan petani beralih tanaman kakao menjadi tanaman lada. Variabel usia mempunyai koefisien Exp (B) sebesar 0,851 dan bertanda negatif pada koefisien B yang berarti setiap perubahan usia sebesar 1 tahun maka rasio kemungkinan petani beralih tanaman kakao menjadi tanaman lada bertambah sebesar 0,851 (probabilitas 0 - 1). Hal tersebut menunjukkan bahwa semakin muda usia petani, maka peluang petani untuk beralih tanaman kakao menjadi tanaman lada lebih besar 0,851 kali dibandingkan petani tetap menanam kakao. Menurut Kaizan (2014), semakin tua petani maka peluang untuk merubah suatu usahatani yang sudah biasa petani lakukan akan berkurang karena kemampuan petani yang semakin rendah.
Tingkat pendidikan $\left(\mathrm{X}_{2}\right)$, variabel pendidikan tidak berpengaruh nyata terhadap keputusan petani beralih tanaman kakao menjadi tanaman lada. Variabel tingkat pendidikan mempunyai koefisien $\operatorname{Exp}$ (B) sebesar 0,810 dan bertanda negatif pada koefisien B yang berarti bahwa setiap perubahan tingkat pendidikan sebesar 1 tingkat maka rasio kemungkinan petani beralih tanaman kakao menjadi tanaman lada berkurang sebesar 0,767 tahun. Hal tersebut menunjukkan bahwa keputusan petani memilih tanaman terbaik tidak tergantung pada lamanya petani mengeyam pendidikan formal di bangku sekolah, namun lebih kepada pengalaman berusahatani yang pernah dilakukannya (Kaizan, 2014). Menurut Kusumo et al (2018), pendidikan tidak berpengaruh secara signifikan terhadap pengambilan keputusan petani. Sejalan dengan penelitian Anisah et al (2017) yang menyatakan bahwa tingkat pendidikan tidak berpengaruh nyata terhadap pengambilan keputusan petani dalam berushatani cabe jamu.

Jumlah tanggungan $\left(X_{3}\right)$, variabel jumlah tanggungan berpengaruh nyata terhadap keputusan petani beralih tanaman kakao menjadi tanaman lada. Variabel jumlah tanggungan keluarga 


\section{KEPUTUSAN PETANI BERALIH USAHATANI DARI TANAMAN KAKAO MENJADI LADA \\ DI KABUPATEN LAMPUNG TIMUR \\ Zulkarnain, Muher Sukmayanto}

mempunyai koefisien Exp (B) sebesar 2,965 bertanda positif pada koefisien B, yang berarti bahwa setiap penambahan jumlah tanggungan keluarga sebanyak 1 orang maka kemungkinan petani beralih tanaman kakao menjadi tanaman lada bertambah sebanyak 2,965 orang. Hal tersebut menunjukkan bahwa semakin banyak jumlah tanggungan keluarga yang dimiliki, maka kebutuhan hidup akan semakin besar juga, hal ini menyebabkan petani mencoba peluang usahatani lain yang menjanjikan keuntungan yang lebih besar maka peluang petani untuk beralih tanaman kakao menjadi tanaman lada lebih besar dibandingkan petani tetap menanam kakao.

\section{Pengalaman usahatani $\left(X_{4}\right)$,} variabel pengalaman usahatani disini mengacu kepada lamanya seorang petani berusahatani. Variabel pengalaman usahatani berpengaruh nyata terhadap keputusan petani beralih tanaman kakao menjadi tanaman lada. Variabel pengalaman usahatani mempunyai koefisien $\operatorname{Exp}$ (B) sebesar 1,153, dan bertanda positif pada koefisien B yang berarti bahwa setiap penambahan pengalaman usahatani selama 1 tahun maka rasio kemungkinan petani beralih tanaman kakao menjadi tanaman lada bertambah sebesar 1,153 (probabilitas 0 1). Hal tersebut menunjukkan bahwa semakin banyak pengalaman usahatani, maka peluang akan lebih mampu mengambil keputusan yang tepat dalam menentukan tanaman terbaik yang dapat meningkatkan pendapatan. Keberhasilan petani memilih jenis tanaman ikut ditentukan pula oleh pengalaman orang tua, rekan-rekannya dan dari media informasi.

Luas lahan $\left(X_{5}\right)$, variabel luas lahan tidak berpengaruh nyata terhadap keputusan petani beralih tanaman kakao menjadi tanaman lada. Variabel luas lahan mempunyai koefisien Exp (B) sebesar 3,589, dan bertanda positif pada koefisien B yang berarti bahwa setiap penambahan luas lahan 1 hektar maka kemungkinan petani mengkonversi lahan kakao menjadi tanaman lada bertambah sebesar 3,589 hektar. Hal tersebut menunjukkan bahwa semakin luas lahan yang dimiliki, maka peluang petani untuk mengkonversi tanaman kakao menjadi tanaman lada lebih besar dibandingkan petani tetap menanam kakao. Penambahan luas lahan dapat menurunkan peluang petani untuk menganti tanaman kakao menjadi tanaman lada. Sejalan dengan penelitian Harahap (2017) dan Ginanjar et al. (2017) yang menyatakan luas lahan tidak berpengaruh nyata pada proses pengambilan keputusan yang dilakukan oleh petani. 
Pendapatan $\quad\left(X_{6}\right), \quad$ variabel pendapatan berpengaruh nyata terhadap keputusan petani mengkonversi tanaman kakao menjadi tanaman lada. Variabel pendapatan mempunyai koefisien sebesar 1,001 , yang berarti bahwa setiap perubahan pendapatan sebesar 1 rupiah maka kemungkinan petani mengkonversi lahan kakao menjadi tanaman lada bertambah sebesar 1,00 rupiah. Pendapatan usahatani yang diperoleh dari pemanfaatan lahan oleh petani dengan menanam tanaman kakao atau lada pada lahan tertentu memiliki pengaruh terhadap keputusan petani menganti tanaman kakao menjadi tanaman lada secara nyata pada taraf kepercayaan $95 \%$. Apabila pendapatan yang dihasilkan dari suatu tanaman semakin besar maka peluang petani akan mengambil keputusan untuk memilih tanaman yang memberikan pendapatan yang lebih besar, sebaliknya semakin kecil pendapatan yang diperoleh dari suatu tanaman maka kemungkinan peluang petani akan memilih tanaman tersebut semakin kecil. Berdasarkan hasil penelitian, pendapatan usahatani lada sebesar Rp 25.769.452,67 dan usahatani kakao sebesar Rp 17.203.661,06. Sejalan dengan Apriliana dan Mustadjab (2016) serta Dilla, (2014) yang menyatakan bahwa semakin tinggi tingkat pendapatan petani, maka akan semakin tinggi kecenderungan petani untuk memutuskan beralih tanaman yang lebih besar pendapatannya.

\section{KESIMPULAN}

Faktor-faktor yang mempengaruhi keputusan petani beralih usahatani dari tanaman kakao ke lada adalah usia petani, tanggungan keluarga, pengalaman usahatani, dan pendapatan petani.

\section{DAFTAR PUSTAKA}

Anisah, \& Hayati, M. (2017). Pengambilan Keputusan Petani untuk Tetap Berusahatani Cabe Jamu di Kecamatan Bluto, Kabupaten Sumenep. Journal of Agribusiness and Rural Development Research, 3(2), 112118. DOI: https://doi.org/10.18196/ agr.3251

Apriliana, M.A., \& Mustadjab, M.M. (2016). Analisis Faktor-Faktor Yang Mempengaruhi Petani Dalam Menggunakan Benih Hibrida Pada Usahatani Jagung (Studi Kasus di Desa Patokpicis, Kecamatan Wajak, Kabupaten Malang). Jurnal HABITAT, 27(1), 7-13. DOI: https://doi.org/10.21776/ub.habitat. 2016.027.1.2

Dinas Perkebunan dan Kehutanan. (2016). Jumlah Petani di Desa Margatiga. Kabupaten Lampung Timur.

Fitriana, N., Tarumun, S., \& Tety, E. 2014. Analisis Daya Saing Biji Kakao (Cocoa beans) Indonesia di Pasar Internasional. Jom Faperta, 1(2), 1-12.

Ginanjar G., Ayu, S.A., \& Dinar. (2017). Analisis Faktor-Faktor Yang Mempengaruhi Pengambilan Keputusan Petani Melakukan 


\section{KEPUTUSAN PETANI BERALIH USAHATANI DARI TANAMAN KAKAO MENJADI LADA \\ DI KABUPATEN LAMPUNG TIMUR \\ Zulkarnain, Muher Sukmayanto}

Usahatani Jagung Hibrida. Jurnal Ilmu Pertanian dan Peternakan, 5(2), 130-136.

Harahap, J., Sriyoto, S., \& Yuliarti, E. (2018). Faktor-Faktor Yang Mempengaruhi Pengambilan Keputusan Petani Salak Dalam Memilih Saluran Pemasaran. Jurnal AGRISEP, 17(1), 95-106.

Hasibuan, A.M., Nurmalina, R., \& Wahyudi, A. (2012). Pengaruh Pencapaian Kebijakan Penerapan Bea Ekspor dan Gernas Kakao Terhadap Kinerja Industri Hilir dan Penerimaan Petani Kakao (Suatu Pendekatan Dinamika Sistem). Buletin Riset Tanaman Rempah dan Aneka Tanaman Industri, 3(2), 157170.

DOI: http://dx.doi.org/10.21082/jtidp.v3n 2.2012.p157-170

Kaizan, 2014. Analisis Kelayakan Finansial dan Nilai Ekonomi Lahan (Land Rent) Pada Penggantian Usahatani Kopi Menjadi Karet di Kabupaten Way Kanan Propinsi Lampung (Tesis). Jurusan Magister Agribisnis. Universitas Lampung. Lampung.

Kaplale, R. (2015). Analisis Tingkat Usahatani Kakao (Theobroma cacao L.) Studi Kasus di Desa Latu Kecamatan Amalatu Kabupaten Seram Bagian Barat. Jurnal Ilmiah agribisnis dan Perikanan (agrikan UMMU-Ternate), 4(2), 60-68.

Kementerian Pertanian. (2018). Outlook Lada Komoditas Subsektor Perkebunan. Pusat Data dan Sistem Informasi Pertanian. Jakarta.

Kusumo, R.A. B., Rasmikayati, E., Mukti, G. W., Fatimah, S., \& Saefudin, B. R. (2018). Faktor-Faktor Yang Mempengaruhi Keputusan Petani Mangga Dalam Menggunakan Teknologi Off Season Di Kabupaten Cirebon. Jurnal MIMBAR AGRIBISNIS: Jurnal Pemikiran
Masyarakat Ilmiah Berwawasan Agribisnis, 4(1), 57-69.

Makeham dan Malcolm. (1991). Manajemen Usahatani Daerah Tropis. Penerbit LP3ES. Jakarta.

Maulana, A., \& Kartiasih, F. (2017). Analisis Ekspor Kakao Olahan Indonesia ke Sembilan Negara TujuanTahun 2000-2014. Jurnal Ekonomi dan Pembangunan Indonesia, 17(2), 103-117. DOI: http://dx.doi.org/10.21002/jepi.v17i 2.664103

Nurfathiyah P., Denmar, D., \& Prasakti, T. (2007). Faktor-Faktor Yang Melatarbelakangi Keputusan Petani Dalam Mengusahakan Komoditi Karet Di desa Pasar Terusan Kecamatan Muara Bulian. Jurnal Ilmiah Sosio-Ekonomika Bisnis. 13(1), 1-11. DOI: https://doi.org/10.22437/jiseb.v13i1 .298

Riani. (2015). Analisis Pendapatan Usahatani Kakao di desa Sidole Kecamatan Ampibabo Kabupaten Parigi Moutong. e-j Agrotekbis, 3(6), 779-785.

Rizal, R. K., Hasyim, A.I., \& Situmorang, S. (2017). Kelayakan Ekonomi dan Pemasaran Kakao di Kabupaten Lampung Selatan. Jurnal Ilmu-Ilmu Agribisnis, 5(4): 384-391.

Rubiyo, \& Siswanto. (2012). Peningkatan Produksi dan Pengembangan Kakao (Theobroma Cacao L.) di Indonesia. Buletin Riset Tanaman Rempah dan Aneka Tanaman Industri, 3 (1), 3348.

DOI:

http://dx.doi.org/10.21082/jtidp.v3n 1.2012.p33-48.

Sugiarto, D. Siagian, L.S. Sunarto, dan D.S. Oetomo. 2003. Teknik Sampling. Jakarta: Gramedia Pustaka Utama.

Sumantri, B., Priyono, B.S., \& Isronita, M. (2004). Analisis Kelembagaan

Finansial Usahatani Lada (Piper nigrum, $L)$ di Desa Kunduran Kecamatan 
Ulu Musi Kabupaten Lahat Sumatra Selatan. Jurnal Ilmu-Ilmu Pertanian Indonesia, 6(1): 32-42.

Soekartawi. (1990). Teori Ekonomi Produksi. Raja Grafindo Persada. Jakarta.

Suryana, A. T., Fariyanti, A., \& Rifin, A. (2014). Analisis Perdagangan Kakao Indonesia di Pasar Internasional. Jurnal Tanaman Industri dan Penyegar, 1(1), 29-40. DOI: $\quad$ http://dx.doi.org/10.21082/ jtidp.v1n1.2014.p29-40.
Suwanto, 2017. Analisis Daya Saing dan Pemasaran Lada Hitam di Kabupaten Lampung Timur (Tesis). Jurusan Magister Agribisnis. Universitas Lampung. Lampung.

Syamsuddin, \& Muhammad, H. (2014). Analisis Potensi dan Peluang Pengembangan Kakao di Sulawesi Barat. Jurnal Agros, 16(1): 92-101. Widarjono, A. (2016). EKONOMETRIKA Pengantar dan Aplikasinya. UPP STIM YKPN. Yogyakarta 